\title{
Effect of Processing, Packaging and Vibration Treatment on the Sensory Quality of Fresh- cut Apple Slices
}

\author{
By M. Siddiq, ${ }^{1 *}$ J. B. Harte, ${ }^{1}$ S. P. Singh, ${ }^{2}$ A. A. Khan, ${ }^{1 \#}$ K. D. Dolan ${ }^{1,3}$ and K. Saha ${ }^{4}$ \\ ${ }^{1}$ Department of Food Science and Human Nutrition, Michigan State University, East Lansing, MI 48824, USA \\ ${ }^{2}$ School of Packaging, Michigan State University, East Lansing, MI 48824, USA \\ ${ }^{3}$ Department of Biosystems and Agricultural Engineering, Michigan State University, East Lansing, MI 48824, \\ USA \\ ${ }^{4}$ Packaging Program, Industrial Technology, Cal Poly State University, San Luis Obispo, CA 93407, USA \\ SUMMARY
}

Fresh-cut fruit industry has seen tremendous growth in recent years. The present study was designed with the objective of studying the sensory quality of fresh-cut apple slices that were treated with different antibrowning agents, packed in three types of packaging materials and subjected to vibration treatment to simulate commercial transportation. The slices were treated with two commercial antibrowning agents [NatureSeal (Mantrose-Haeuser Co., Inc., Westport, CT, USA) and Ever-Fresh (Kraft Foods, Inc., Rye Brook, NY, USA)] at 5\% (w/v) application rate. The treated slices were packaged in $5 \mathrm{oz}$ polystyrene rigid container, $2 \mathrm{lb}$ polyethylene bag or $2 \mathrm{oz}$ polyethylene bag. A nine-member trained panel and a 100-member consumer panel evaluated the treated slices for selected sensory attributes. The trained sensory small panel found minimal difference in the fresh-cut slices in comparison with the control (non-vibrated) sample, with the slices treated with NatureSeal better in quality than those treated with EverFresh. Case positions (bottom, middle or top) within the vibration stack did not affect the quality of the slices significantly; similar results were found from the consumer panel sensory evaluation. The consumer panel evaluation results showed that the slices treated with 
NatureSeal were better in sensory attributes of colour, texture, flavour and overall acceptability.

Overall, package type had no or minimal effect on the slice quality attributes.

KEY WORDS: fresh-cut slices; apple; transport vibration; packaging; sensory quality

\section{INTRODUCTION}

Fresh-cut produce is defined as any fresh fruit or vegetable or any combination thereof that has been physically altered from its original form but remains in a fresh state. ${ }^{1}$ Fresh-cut produce also called 'minimally processed' has two main purposes: (a) keeping the produce fresh by extending its shelf life without losing its nutritional and sensory quality or compromising product safety and (b) ensuring a product shelf life that is sufficient to make its distribution feasible within the region of its consumption. ${ }^{2,3}$ Fresh-cut produce is one of the fastest growing segments of the food industry in the USA. ${ }^{4}$

Quality factors for fresh-cut products include visual appearance (freshness, colour, defects and decay), texture or firmness, flavour, nutritive value and microbial safety. ${ }^{5,6}$ Many of these quality attributes are susceptible to negative change during shipping and distribution channels. From the consumers' perspective, colour or appearance is the most important quality; if the colour of a fresh-cut product is not attractive or of acceptable quality, the consumer is less likely to purchase it regardless of its excellent texture, flavour, taste or other quality attributes. ${ }^{7}$ Therefore, in addition to acceptable physicochemical properties, high level of sensory quality is a prerequisite for successful marketing of fresh-cut fruits and vegetables.

Post-processing, distribution logistics for fresh-cut apples present significant challenges in maintaining the optimum quality. In the USA, most of the processors are located near the 
centres of crop production, and processed products are shipped as far as 2000 miles by the national processors. ${ }^{8}$ In addition to the processing operations, fresh-cut products are also subjected to stress during the physical action of transportation, such as continuous vibration.

Most of the past studies on fresh-cut apple slices have focused on the determination of instrumental colour sensory or microbial quality as affected by antibrowning or sanitizer treatments, ${ }^{9-12}$ whereas vibration impact studies have focused mainly on the whole ${ }^{13-15}$ package performance or optimization ${ }^{16,17}$ and vibration dynamic or models. ${ }^{18,19}$ However, there is little, if any, documentation on the effect of vibration impact during transportation on the sensory quality and the consumer preferences for fresh-cut apple slices in different types of packages. Our objective was to investigate the impact of simulated transportation and package type on the sensory quality of fresh-cut apple slices pre-treated with two antibrowning treatments.

\section{MATERIALS AND METHODS}

Empire apples treated with 1-methylcyclopropene (1-MCP), an ethylene inhibitor, and stored under controlled atmosphere conditions for approximately 8 months were purchased locally. These apples were harvested at the same maturity stage. The reason for using 8 month stored apples was that the fruit must store well and be available throughout the year to meet the freshcut processors’ demand.

Slice processing

Apples were washed using tap water and then dipped in Fruit \& Vegetable Wash (SC Johnson Professional, Sturtevant, WI, USA) for $5 \mathrm{~min}$ at a concentration to yield $160 \mathrm{ppm}$ of available Ichlorine. Apples were then sliced using an automatic corer/slicer (Bock Engineered Products, Inc., Toledo, OH, USA) with a 10-cut blade. Cut slices were dipped in the antibrowning treatment solutions $\left(5 \mathrm{~g} 100 \mathrm{ml}^{-1}\right.$ ) for $\sim 30 \mathrm{~s}$. The antibrowning treatments used were NatureSeal, 
calcium salt of ascorbic acid, and Ever-Fresh, with ascorbic and citric acids as main ingredients. NatureSeal is a widely used antibrowning treatment, ${ }^{11}$ whereas Ever-Fresh is used in food service applications. The treated apple slices were packaged in $5 \mathrm{oz}$ polystyrene (PS) rigid container, $2 \mathrm{lb}$ polyethylene (PE) bag or 2 oz PE bag. Table 1 shows package weights, packages per case and case dimensions.

To allow gas exchange with the external environment, which was comparable to the commercially available microperforated packaging materials, an initial test was done, and appropriate numbers of pinholes were made on each package (Table 1).

\section{[Insert Table 1]}

\section{Packaging and vibration impact}

A total of 20 cases, 10 each for control and vibration treatment, of each package type (shown in Table 1) were prepared for the slices treated with both antibrowning agents. The packaged slices were stored at $4^{\circ} \mathrm{C}$ for $24 \mathrm{~h}$ before vibration testing that was conducted at room temperature $\left(\sim 23^{\circ} \mathrm{C}\right)$. Prior to the vibration testing, 10 cases in the column were labelled 1 to 10 (top to bottom), with the following case positions (for trained panel sensory evaluation): top (cases 1-3), middle (cases 4-7) and bottom (cases 8-10). The vibration tests were conducted to simulate the hazards of the truck transportation environment. A column stack of 10 cases of each package type was subjected to a random vibration test in accordance with American Society for Testing and Materials (ASTM) D4728. The composite truck spectrum described in ASTM D4169 Assurance Level II was used for 60 min vibration. The overall root-mean-square acceleration (Grms) of the vibration test was $0.52 \mathrm{G} .{ }^{20}$ These vibration conditions represent an accelerated test for approximately 500 miles of interstate highway shipment. After package 
vibration application, the slices were stored at $4^{\circ} \mathrm{C}$ for 9 days (10 days post-processing) before sensory evaluation.

Sensory evaluation

Michigan University’s Biomedical and Health Sciences Intuitional Review Board approved the study protocol for sensory evaluations of fresh-cut slices.

Trained panel. The trained panel consisted of nine members, and training was conducted in three orientation sessions where panellists developed rating scales for the degree of browning and overall appearance. For training purposes and familiarisation, panellists were offered slices of varying degree of quality for the degree of browning and overall appearance.

Panellists performed 'difference from control' discrimination sensory test for the degree of browning and overall appearance for the slices from each type of package and the three case positions (top, middle and bottom) on a 0-8 scoring scale $(0=$ no difference from control; $8=$ extremely different from control). For each sample, three to four slices were placed randomly numbered 8 oz cups and presented randomly to avoid panellists' bias. Evaluation was conducted at room temperature in individual booths under white fluorescent light.

Consumer panel. The 100-member consumer panel comprised of a broad cross-section of adult population. The individual case positions were not evaluated in this evaluation; rather, samples from different cases were mixed for each treatment before evaluation. Sample preparation and presentation were the same as that for the trained panel evaluation. Panellists were asked to rate their likeness for colour, texture, flavour and overall acceptability on a 1-9 hedonic scale: ${ }^{21} 1$ = dislike extremely, 2 = dislike very much, 3 = dislike moderately, 4 = dislike slightly, 5 = neither like nor dislike, 6 = like slightly, 7 = like moderately, 8 = like very much 
and 9 =like extremely). A score of 5 or below was considered a limit of acceptability for all sensory attributes evaluated.

\section{Statistical analysis}

All data were analysed by analysis of variance using SAS software, version 9.1 (SAS Institute, Inc., Cary, NC, USA). The separation of means or significant differences was made by Tukey's Honestly Significant Difference, and the statistical significance was defined as $\mathrm{p}<0.05$.

\section{RESULTS AND DISCUSSION}

\section{Trained panel sensory evaluation}

Sensory evaluation by the trained panel showed that the NatureSeal application preserved the appearance of the apple slices and that the vibration testing did not produce any detectable changes in the apple slice quality (Table 2). The overall appearance and browning scores for the samples in rigid containers, which were treated with Ever-Fresh, were significantly higher (representing greater difference from control) after vibration testing in the top case position compared with that in the bottom position. Because cases on the top do not have as much weight on them, they could potentially have the greatest amount of movement during testing. This indicated that any quality changes due to vibration were not severe. Except for the slices in the middle case position in the $2 \mathrm{lb}$ PE bags evaluated on day 10, no significant differences in the degree of browning or overall appearance were observed regardless of the antibrowning treatment used or the other two case positions. This was due probably to the fact that during vibration, slices in the middle case position bags were hitting against cut-slice edges on both sides in the top and bottom position bags; this may have resulted in some tissue damage to initiate browning. It is noted that variation in apple slices, both naturally occurring and as a result of small process variation, can have some effect. 
[Insert Table 2]

Consumer panel sensory evaluation

Colour. The non-vibrated (control) slices treated with NatureSeal had significantly $(\mathrm{p}<0.05)$ better colour scores, 6.53 to 6.80, than those treated with Ever-Fresh, which ranged from 3.99 to 4.58 (Figure 1). None of the Ever-Fresh-treated samples (control or vibrated) were in the acceptable quality range (sensory colour score of 5 or less was considered the limit of acceptable quality). Package type had minimal effect on colour scores for the NatureSeal-treated slices, whereas the Ever-fresh-treated slices in 5 oz rigid PS containers fared better than those in the other two packages; probably, 5 oz package's rigid construction provided extra protection. In general, there was slight colour deterioration, although not significant $(\mathrm{p}<0.05)$, as a result of vibration treatment regardless of antibrowning treatments or type of package.

Texture. With the exception of the slices in the 2 lb PE bags, vibration of slices within each antibrowning treatment had no significant effect on texture as compared with the non-vibrated samples (Figure 1). Texture scores ranging from 6.15 to 6.57 were observed with NatureSeal across the three package types, with the highest degree of preference (6.57) in the PS rigid container followed by the $2 \mathrm{oz}$ and $2 \mathrm{lb}$ PE bags, respectively. Slices treated with Ever-Fresh had texture scores ranging from 5.28 to 5.94. Again, highest texture scores were obtained with samples packed in PS rigid containers. However, Ever-Fresh was consistently less effective in maintaining texture than NatureSeal in all the three packages. Overall, the slices in the 5 oz PS rigid container had the best texture scores as compared with that of the two other package types. The apples used in this study were pre-treated with 1-MCP; Perera et al. ${ }^{22}$ reported that 1-MCP treatment was effective in reducing ethylene production, respiration and loss of firmness of slices when applied to whole apples directly after harvest. 


\section{[Insert Figure 1]}

Flavour. There were no significant $(\mathrm{p}<0.05)$ differences in flavour scores either between the two antibrowning treatments or as a result of vibration impact (Figure 1). The best flavour score of 6.13 was observed in the NatureSeal-treated slices in the 2 oz PE bags that were subjected to vibration; in comparison, the Ever-Fresh-treated and Ever-Fresh-vibrated slices in the $2 \mathrm{lb}$ PE bags had the lowest flavour score of 5.41. Although not significant, generally, the vibration impact appeared to have slightly enhanced the flavour. One possible explanation for this enhanced flavour might be the constant rubbing of slices with each other during vibration that may have released flavour volatiles. This was in contrast to the effect observed for colour, where vibration had an inverse impact on most samples. Beaulieu and Baldwin suggested that if disruption of the skin occurs by cutting, the rate of respiration is accelerated, and the characteristic flavour and aroma compounds in fruit are modified. ${ }^{23}$

Overall acceptability. Consistently, higher overall acceptability scores were observed for the NatureSeal-treated slices in all three types of packages (Figure 1). Among all package types and antibrowning treatments, the lowest overall acceptability scores were found for the slices packaged in the $2 \mathrm{lb}$ PE bags. The vibration treatment had a minimal impact on apple slices regardless of the package type or the antibrowning treatment used. The overall acceptability scores lower than the limit of acceptability (i.e. $<5$ ) were observed only in the Ever-freshtreated slices in the $2 \mathrm{lb}$ PE bags, for both the control (4.91) and vibrated samples (4.65). Sensory quality of fresh-cut fruits can be further improved by the use of modified atmosphere packaging. $^{24}$

Figure 2 shows the frequency distribution of overall acceptability scores for the fresh-cut apple slices in three types of packages that were subjected to vibration. For the NatureSeal- 
treated apple slices, $79-88 \%$ respondents rated overall acceptability at a score of $\geq 6$, which is a significantly higher proportion as compared with the Ever-Fresh-treated slices where only 5576\% panellists gave a score of 6 or higher.

[Insert Figure 2]

\section{CONCLUSIONS}

This study was undertaken to compare the effect of commercial antibrowning treatments of fresh-cut apple slices packaged in PS rigid containers or small and large PE bags and subjected to simulated transportation vibration. The PS rigid container performed better in preserving the sensory attributes studied. The vibration impact on the fresh-cut apple slices was minimal regardless of the package type. The results of this study demonstrated that fresh-cut slices treated with NatureSeal can be successfully transported and marketed, in any of the three types of packages investigated, without any significant impact on major sensory attributes.

\section{REFERENCES}

1. IFPA 2004. Fresh-cut Produce/Fresh-cut Process. International Fresh-Cut Produce Association: Alexandria, VA; http:// www.fresh-cuts.org/ [accessed 26 July 2005].

2. Vasconellos JA. Regulatory and safety aspects of refrigerated minimally processed fruits and vegetables: a review. In Minimally Processed Fruits and Vegetables, Alzamora SM, Tapia MS, Lopez-Malo A (eds). Aspen Publishers: Gaithersburg, MD, 2000; 319-343.

3. Laurila E, Ahvenainen R. Minimal processing in practice. In Minimal Processing Technologies in the Food Industry, Ohlsson T, Bengtsson N (eds). Woodhead Publishing Ltd: Cambridge, 2002; 223.

4. Rowles K, Henniehan B, White G. Thinking Afresh About Processing: an Exploration of New Market Opportunities for Apple Products. Staff Paper 2001-03, Cornell University, 
Department of Applied Economics and Management, College of Agriculture and Life Sciences, 2001.

5. Kader AA, Mitcham B. Standardization of quality. In Fresh-cut Products—Maintaining Quality and Safety. University of California: Davis, CA, 1996.

6. Piagentini AM, Guemes DR, Pirovani ME. Sensory characteristics of fresh-cut spinach preserved by combined factors methodology. Journal of Food Science 2002; 67: 1544-9.

7. Siddiq M. Peaches and nectarines. In Handbook of Fruits and Fruit Processing, Hui Y (ed.). Blackwell Publishing Co.: Ames, IA, 2006; 519-531.

8. Watada AE, Qi L. Quality of fresh-cut produce. Postharvest Biology and Technology 1999; 15: 201-205.

9. Abbott JA, Saftner RA, Gross KC, Vinyard BT, Janick J. Consumer evaluation and quality measurement of fresh-cut slices of 'Fuji’, ‘Golden Delicious’, ‘GoldRush’ and ‘Granny Smith’ apples. Postharvest Biology and Technology 2004; 33: 127-140.

10. Buta JG, Moline HE, Spaulding DW, Wang CY. Extending storage life of fresh-cut apples using natural products and their derivatives. Journal of Agricultural and Food Chemistry 1999; 47: 1-6.

11. Pilizota V, Sapers GM. Novel browning inhibitor formulation for fresh-cut apples. Journal of Food Science 2004; 69:140-143.

12. Toivonen PMA. Influence of harvest maturity on cut-edge browning of 'Granny Smith' fresh apple slices treated with anti-browning solution after cutting. LWT Food Science and Technology 2008; 41:1607-1609.

13. Chonhenchob V, Singh SP. Packaging performance comparison for distribution and export of papaya fruit. Packaging Technology and Science 2005; 18: 125-131. 
14. Jarimopas BPS, Singh P, Sayasoonthorn S, Singh J. Comparison of package cushioning materials to protect post-harvest impact damage to apples. Packaging Technology and Science 2007; 20: 315-324.

15. Chonhenchob V, Kamhangwong D, Singh SP. Comparison of reusable and single-use plastic and paper shipping containers for distribution of fresh pineapples. Packaging Technology and Science 2008; 21: 73-83.

16. Rouillard V, Sek MA. Monitoring and simulating non-stationary vibrations for package optimization. Packaging Technology and Science 2000; 13: 149-156.

17. Sek MA. A modern technique of transportation simulation for package performance testing. Packaging Technology and Science 1996; 9: 327-343.

18. Bernad C, Laspalas A, González D, Liarte E, Jiménez MA. Dynamic study of stacked packaging units by operational modal analysis. Packaging Technology and Science 2010; 23: $121-133$.

19. Ge C. Model of accelerated vibration test. Packaging Technology and Science 2000; 13: 711.

20. ASTM. ASTM Standards, Volume 15.09: Packaging. American Society of Testing and Materials: West Conshohocken, PA, 2003.

21. Meilgaard M, Civille GV, Carr BT. Affective tests: consumer tests and in-house panel acceptance tests. In Sensory Evaluation Techniques, 3rd edn. CRC Press: Boca Raton, FL, 1999; 242-243.

22. Perera CO, Balchin L, Baldwin E, Stanley R, Tian M. Effect of 1-methylcyclopropene on the quality of fresh-cut apple slices. Journal of Food Science 2003; 68: 1910-1914. 
23. Beaulieu JC, Baldwin EA. Flavor and aroma of fresh-cut fruits and vegetables. In Fresh-cut

Fruits and Vegetables, Lamikanra O (ed.). CRC Press: Boca Raton, FL, 2002; 391-425.

24. Chonhenchob V, Chantarasomboon Y, Singh SP. Quality changes of treated fresh-cut

tropical fruits in rigid modified atmosphere packaging containers. Packaging Technology

and Science 2007; 20: 27-37.

Table 1. Specifications and package details used for evaluating the quality of the fresh-cut apple slices.

\begin{tabular}{|c|c|c|c|c|c|}
\hline Type of package & $\begin{array}{l}\text { Serving } \\
\text { size }\end{array}$ & $\begin{array}{l}\text { Size } \\
\text { (inch) }\end{array}$ & $\begin{array}{l}\text { Slices per } \\
\text { package }\end{array}$ & $\begin{array}{c}\text { Packages per } \\
\text { case }\end{array}$ & $\begin{array}{c}\text { Slices per case } \\
\text { (lbs) }\end{array}$ \\
\hline $\begin{array}{l}\text { PS rigid package, with six } \\
\text { pinholes }^{\mathrm{a}}\end{array}$ & Individual & $3.75 \times 5.0$ & $5 \mathrm{oz}$ & 12 & 3.75 \\
\hline PE bag, with 12 pinholes ${ }^{\mathrm{b}}$ & Food service & $11.0 \times 14.0$ & $2 \mathrm{lb}$ & 6 & 12.00 \\
\hline PE bag, with two pinholes ${ }^{\mathrm{c}}$ & School lunch & $4.0 \times 6.0$ & $2 \mathrm{oz}$ & 60 & 7.50 \\
\hline
\end{tabular}

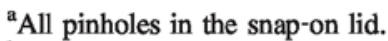

${ }^{b}$ Six pinholes on each side.

${ }^{c}$ One pinhole on each side.

Table 2. Small panel sensory evaluation of the fresh-cut apple slices for the degree of browning and overall acceptability (difference from control test performed on a $0-8$ scale: $0=$ no difference, $8=$ maximum difference).

\begin{tabular}{|c|c|c|c|c|c|c|c|c|c|}
\hline \multirow[b]{3}{*}{ Package type } & \multirow{3}{*}{$\begin{array}{c}\text { Case } \\
\text { position }\end{array}$} & \multicolumn{4}{|c|}{ Degree of browning } & \multicolumn{4}{|c|}{ Overall appearance } \\
\hline & & \multicolumn{2}{|c|}{ NatureSeal } & \multicolumn{2}{|c|}{ Ever-Fresh } & \multicolumn{2}{|c|}{ NatureSeal } & \multicolumn{2}{|c|}{ Ever-Fresh } \\
\hline & & Day 3 & Day 10 & Day 3 & Day 10 & Day 3 & Day 10 & Day 3 & Day 10 \\
\hline \multirow[t]{3}{*}{ PS rigid, $5 \mathrm{oz}$} & Top & $6 \mathrm{~b}$ & $0.78 \mathrm{~b}$ & $1.00 \mathrm{ab}$ & 2.44 & $7 \mathrm{~b}$ & $0.67 \mathrm{~b}$ & $\mathrm{ab}$ & 2. \\
\hline & Middle & 0 & 0.8 & $1.11 \mathrm{ab}$ & 1.1 & b & 1.0 & 1. & $a b$ \\
\hline & Bottom & $0.83 \mathrm{~b}$ & $4.67 \mathrm{a}$ & $1.94 \mathrm{ab}$ & $0.67 \mathrm{~b}$ & $1.28 \mathrm{~b}$ & $4.67 \mathrm{a}$ & $2.06 \mathrm{ab}$ & $0.56 \mathrm{~b}$ \\
\hline \multirow[t]{3}{*}{ PE bag, $2 \mathrm{lb}$} & Top & $0.67 \mathrm{ab}$ & $0.67 \mathrm{ab}$ & $0.89 \mathrm{~b}$ & $3.11 \mathrm{a}$ & $0.78 \mathrm{a}$ & $0.67 \mathrm{a}$ & $1.00 \mathrm{~b}$ & $2.78 \mathrm{ab}$ \\
\hline & Middle & $0.56 a b$ & $0.50 \mathrm{~b}$ & $1.33 \mathrm{~b}$ & $3.56 \mathrm{a}$ & $0.89 \mathrm{a}$ & $0.44 \mathrm{~b}$ & $1.33 \mathrm{~b}$ & $3.11 \mathrm{a}$ \\
\hline & Bottom & $0.56 \mathrm{ab}$ & $1.00 \mathrm{a}$ & $2.38 \mathrm{ab}$ & $2.11 \mathrm{ab}$ & $0.56 \mathrm{a}$ & $0.67 \mathrm{a}$ & $2.25 \mathrm{ab}$ & $2.22 \mathrm{ab}$ \\
\hline \multirow[t]{3}{*}{ PE bag, $2 \mathrm{oz}$} & Top & $1.00 \mathrm{a}$ & $0.38 \mathrm{ab}$ & $1.71 \mathrm{a}$ & $1.62 \mathrm{a}$ & $1.14 \mathrm{a}$ & $0.44 \mathrm{~b}$ & $1.29 \mathrm{a}$ & $1.25 \mathrm{a}$ \\
\hline & Middle & $0.71 \mathrm{a}$ & $0.56 \mathrm{a}$ & $1.71 \mathrm{a}$ & $1.50 \mathrm{a}$ & $1.29 \mathrm{a}$ & $0.67 \mathrm{ab}$ & $1.29 \mathrm{a}$ & $1.38 \mathrm{a}$ \\
\hline & Bottom & $0.71 \mathrm{a}$ & $1.00 \mathrm{a}$ & $1.71 \mathrm{a}$ & $1.00 \mathrm{~b}$ & $1.00 \mathrm{a}$ & $1.56 \mathrm{a}$ & $1.43 \mathrm{a}$ & $1.25 \mathrm{a}$ \\
\hline
\end{tabular}

Data for each package type analysed separately; means sharing the same letters in columns are not significantly different $(p<0.05)$. 

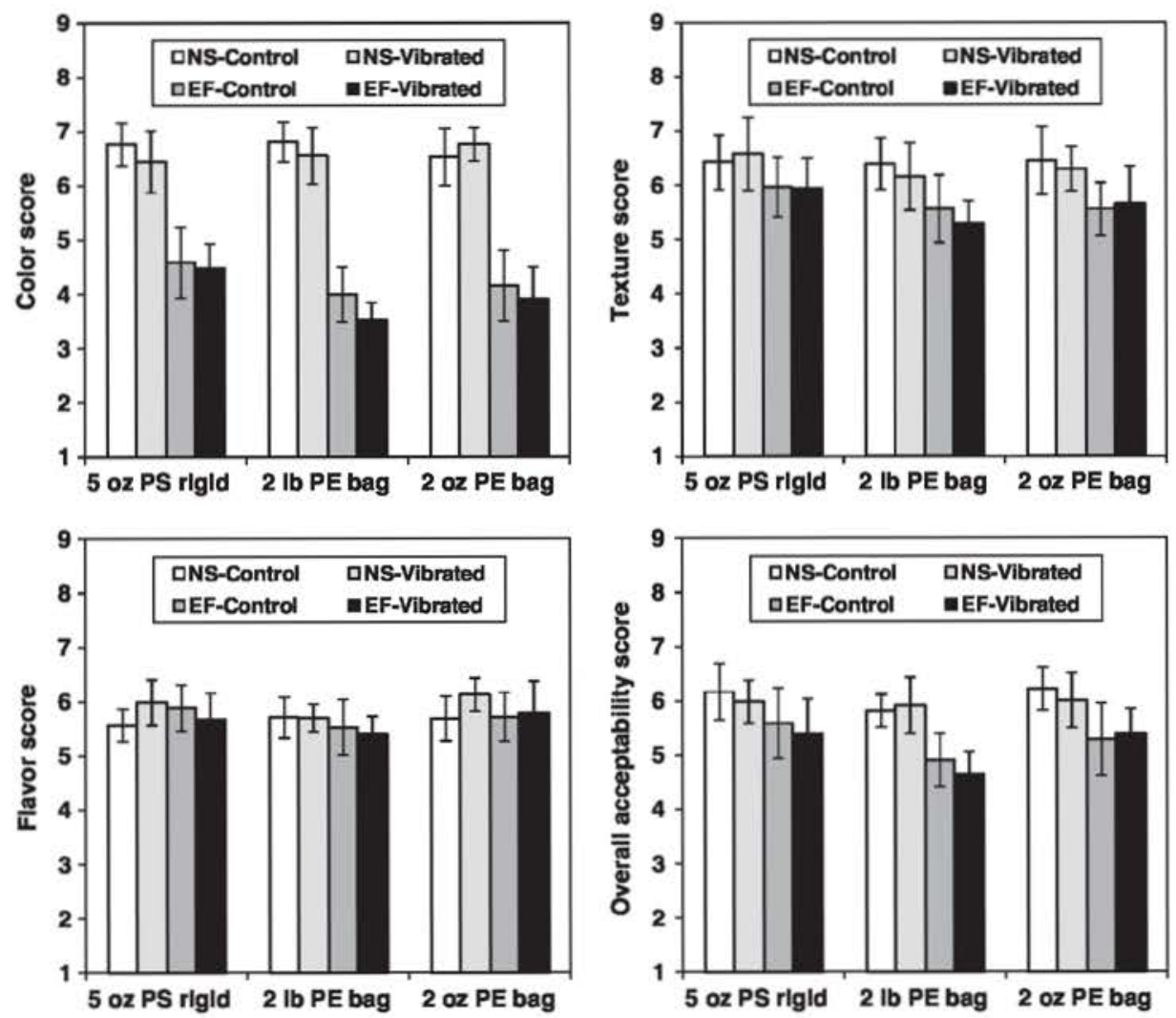

Figure 1. Consumer panel sensory evaluation of the fresh-cut apple slices for colour, texture, flavour and overall acceptability on a $1-9$ hedonic scale $(1=$ dislike extremely, $9=$ like extremely). NS, NatureSeal; EF, Ever-Fresh; PS, polystyrene; PE polyethylene. 

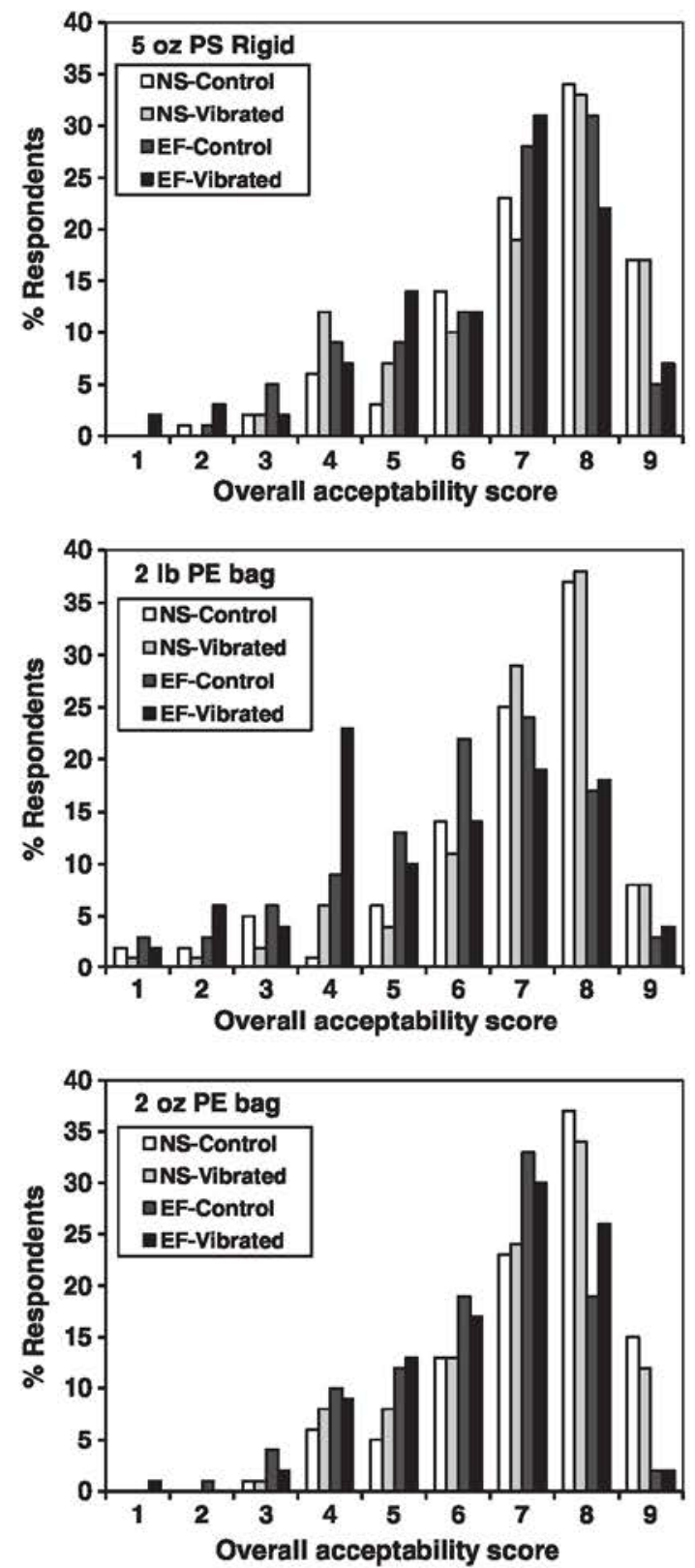

Figure 2. Frequency distribution of the overall acceptability score of the consumer panel sensory evaluation. NS, NatureSeal; EF, Ever-Fresh; PS, polystyrene; PE polyethylene. 